\title{
Dependência espacial da eficiência do uso da terra em assentamento rural na Amazônia
}

\author{
Eliane Gonçalves Gomes Embrapa \\ Célia Regina Grego Embrapa \\ João Carlos Correia Baptista Soares de Mello UFF \\ Gustavo Souza Valladares UFC \\ João Alfredo de Carvalho Mangabeira Embrapa \\ Evaristo Eduardo de Miranda Embrapa
}

\section{RESUMO}

Mudanças no uso e manejo da terra podem ser responsáveis por incrementos na produtividade agrícola. Neste artigo propõe-se o uso de modelos de Análise de Envoltória de Dados (DEA) para avaliar a distribuição espacial da eficiência de agricultores familiares na forma do uso da terra. Estudou-se a evolução da "produtividade da terra" para um grupo de agricultores de Machadinho d'Oeste (RO), para quatro períodos de tempo. As variáveis dos modelos DEA foram as produções de arroz, milho e café como outputs, e a área total plantada dessas culturas como input. Os resultados mostram que o plantio simultâneo de arroz e milho foi a combinação de melhor desempenho. Houve dependência espacial para a eficiência produtiva nos quatro anos avaliados. Os anos de 1999 e 2002 apresentaram maior uniformização em termos da eficiência produtiva dos lotes por toda área, com os lotes mais eficientes concentrando-se na parte central da área de estudo.

Uso da terra, eficiência, dependência espacial.

\section{Spatial dependence of land use efficiency in an Amazon rural settlement}

\begin{abstract}
Agricultural productivity enhancement can be due to land use and land handling changes. In this paper we propose the use of Data Envelopment Analysis models (DEA) to evaluate the spatial distribution of family farmers land use efficiency. We studied the "land productivity" evolution for a sample of family farmers from Machadinho d'Oeste (RO), during four periods of time. DEA models variables were rice, maize and coffee productions as outputs, and these crops total cultivated area as input. As a result we noticed that cultivating simultaneously rice and maize was the best performance case. Efficiency measurements had spatial dependence in the four periods of time. In 1999 and 2002 farms productive efficiency measurements were more uniformly distributed; the most efficient farmers were concentrated in the central part of the studied area.
\end{abstract}

\section{KEY WORDS}

Land use, efficiency, spatial dependence. 


\section{INTRODUÇÃO}

Medidas de produtividade são usualmente usadas para avaliar o desempenho de unidades de produção agrícola. Referem-se genericamente à relação produto-insumo de um dado processo de transformação de uma unidade produtiva, organização ou região. Conforme destacado por Sudit (1995), essas medidas incorporam efeitos de mudança tecnológica e de eficiência (técnica, de escala e alocativa). Diferenças de produtividade decorrem da diversidade das tecnologias de produção, da eficiência do processo de produção e do ambiente no qual o processo produtivo ocorre.

\section{so de modelos DEA para estudar a evolução da produtividade da terra para um grupo de agricultores de Machadinho d'Oeste.}

$\mathrm{O}$ crescimento da produtividade em agricultura tem sido objeto de estudo na literatura. Citam-se, por exemplo, os trabalhos de Thirtle et al. (2008), Tipi e Rehber (2006), Coelli e Rao (2005), Lissitsa e Odening (2005), Perobelli et al. (2005), Vicente (2005), Evenson e Avila (2004), Gasques et al. (2004), Helfand e Levine (2004), Bayarsaihan e Coelli (2003), Toresan (1998), Gasques e Conceição (1997), Coelli (1996), Bureau et al. (1995), Hoffmann e Jamas (1990), entre outros. Esses trabalhos empregam, geralmente, medidas do tipo Produtividade Parcial e Total dos Fatores ou de eficiência DEA-Malmquist (FÄRE et al., 1994).

No setor agrícola, terra e trabalho são fatores básicos de produção e, segundo Alves (2003), produtividade da terra e produtividade do trabalho são duas medidas de desempenho importantes na avaliação em agricultura, em especial para a agricultura familiar. A produtividade da terra é dada pelo quociente entre renda bruta e área total. A produtividade do trabalho é definida pela razão entre renda bruta e o número de trabalhadores. Alves (2003) destaca, entretanto, que não faz sentido estimar simultaneamente as produtividades da terra e do trabalho como definidas.

De forma a avaliar as mudanças na forma de uso e manejo da terra, neste artigo estudou-se a evolução da eficiência produtiva para um grupo de agricultores familiares de Machadinho d'Oeste (RO) e sua variabilidade espacial para quatro períodos de tempo. Nesta região, devido à dificuldade de levantamento de dados econômicos, esta é a medida que melhor expressa o desenvolvimento dos sistemas de produção de base local.
Para medir a eficiência foram usados modelos de Análise de Envoltória de Dados (Data Envelopment Analysis - DEA), um para cada ano estudado. Foram usadas apenas as culturas mais importantes na região, quais sejam, arroz, milho e café. Como variáveis dos modelos DEA foram usadas as produções de arroz, de milho e de café como outputs, e a área total plantada dessas culturas como input. Esta escolha de variáveis faz com que o modelo DEA avalie uma eficiência em relação ao uso da terra. Para não perder relação causal do modelo, desagregaram-se as diferentes culturas mantendose o uso da terra de forma agregada. O modelo foi aplicado para os agricultores que produziram pelo menos uma das culturas em certo ano.

De modo a avaliar a existência de dependência espacial entre as medidas de eficiência foi realizada a análise geoestatística para os quatro períodos avaliados. Em dados amostrados de modo a permitirem análises geoestatísticas tem sido demonstrada a existência de autocorrelação ou de dependência espacial, que deve ser considerada para a interpretação correta dos resultados (VIEIRA et al., 2002). O estudo da variabilidade espacial pode ser um indicativo de determinado local com mais ou menos interferência de fatores como a produtividade das culturas e de solo, no espaço e no tempo. A fertilidade natural dos solos varia na área de estudo (VALLADARES et al., 2003, 2006) e pode influenciar na eficiência dos sistemas de produção. Assim, esta variável pode explicar parte da dependência espacial nesses sistemas de produção com baixo nível tecnológico e de aplicação de insumos, os quais são muito dependentes da reserva natural de nutrientes nos solos.

\section{CARACTERIZAÇÃO DA ÁREA DE ESTUDO}

Machadinho d'Oeste é um município de Rondônia, localizado entre Ariquemes e Jaru, entre as coordenadas geográficas $61^{\circ} 47^{\prime}$ e $63^{\circ} 00^{\prime}$ de longitude WGr e $9^{\circ} 19^{\prime}$ e $10^{\circ} 00^{\prime}$ de latitude $S$, distanciado cerca de $400 \mathrm{~km}$ da capital, Porto Velho.

Antes de ser elevado à condição de município em 1988, Machadinho d'Oeste surgiu como um projeto de assentamento rural (PA). Ao ser instituído como município, seus limites foram ampliados e novas áreas foram incorporadas (quatro outros projetos de colonização e oito centros urbanos), em um total de $8.556 \mathrm{~km}^{2}$.

O PA Machadinho foi dimensionado inicialmente para um total de 3.000 famílias de colonos; mais de 2.000 já haviam chegado em 1984. Nesse ano, esse PA já tinha infraes- 
trutura mínima para a colonização agrícola, como estradas, núcleos urbanos de apoio, projeto fundiário implantado, lotes demarcados etc.

A partir da implementação do assentamento no início dos anos de 1980, a paisagem original tem sido transformada pelos colonos em um mosaico composto por remanescentes florestais, vegetação secundária, pastagens, culturas agrícolas e pequenas áreas urbanizadas. Em Batistella et al. (2000, 2003) e Batistella (2001) encontram-se estudos sobre as mudanças da paisagem e do uso e cobertura das terras em Machadinho d'Oeste.

Em 1986 foi definido um projeto de pesquisa para acompanhar os sistemas de produção agrícola praticados por pequenos agricultores desta região (MIRANDA, 2005). Pesquisas de campo são feitas a cada três anos, com aplicação de questionários com cerca de 250 variáveis agrossocioeconômicas e ambientais, sobre uma amostra de propriedades rurais. A cada ano, o uso das terras é monitorado por imagens de satélites e espacializado em um Sistema de Informações Geográficas (SIG).

No primeiro ano da pesquisa, 1986, foi realizado um esforço de amostragem que cobriu cerca de $15 \%$ dos lotes, em um total de 438 lotes válidos. Essa amostra aleatória e estratificada foi geocodificada em um SIG. Os resultados do primeiro levantamento de dados in loco permitiram definir um perfil inicial dos agricultores recém chegados e de sua agricultura.

Em 1989, um novo levantamento permitiu elaborar e espacializar em SIG o perfil da agricultura e dos agricultores. Em 1993, outra etapa foi realizada, aprofundando aspectos vinculados à economia e ao meio ambiente. A pesquisa de campo de 1996 mostrou que, em dez anos, houve mudanças profundas nas propriedades, tanto na estrutura como nos sistemas de produção (MIRANDA et al., 1997).

Em um novo levantamento de campo em 1999 foram entrevistados 438 agricultores, cujos sistemas de produção foram caracterizados. Caso a propriedade tivesse mudado de dono, o novo responsável era entrevistado e, dessa forma, foi elaborado um novo perfil dos agricultores e da agricultura (MIRANDA et al., 2002).

Em setembro e outubro de 2002, conforme apresentado em Mangabeira et al. (2005), um novo levantamento foi conduzido junto às propriedades estudadas em anos anteriores, com a atualização das variáveis sobre os sistemas de produção praticados. Nessa ocasião, foram entrevistados 327 proprietários.

As publicações referentes a esses 20 anos de pesquisa em Machadinho d'Oeste podem ser encontradas em Miranda (2005). Nessas duas décadas de pesquisa, notaram-se mu- danças na região, seja em relação aos aspectos socioeconômicos, seja em relação ao uso da terra. De modo a avaliar as mudanças na forma de uso da terra, neste artigo fez-se uso de modelos DEA para estudar a evolução da produtividade da terra para um grupo de agricultores dessa localidade.

\section{ANÁLISE DE ENVOLTÓRIA DE DADOS}

Modelos DEA calculam a eficiência relativa de unidades produtivas e usam Problemas de Programação Linear (PPLs), que otimizam cada observação individual de modo a estimar uma fronteira eficiente, linear por partes, composta das unidades que apresentam as melhores práticas (referências ou benchmarks) dentro da amostra em avaliação. É capaz de incorporar diversos inputs (entradas, recursos, insumos ou fatores de produção) e outputs (saídas ou produtos) para o cálculo da eficiência de unidades tomadoras de decisão, designadas por DMUs (Decision Making Units).

\section{emprego de modelos DEA em agricultura pode vir a apoiar as decisões dos agricultores.}

De forma simplificada, a eficiência relativa é definida como a máxima razão entre a soma ponderada das componentes do vetor de produção e a soma ponderada das componentes do vetor de insumos usados no processo de produção. Os pesos usados nas ponderações das componentes de insumos e produtos são distintos e obtidos dos PPLs de DEA.

Há dois modelos DEA clássicos. O modelo CCR (também conhecido por CRS ou constant returns to scale) assume retornos constantes de escala (CHARNES et al., 1978) e proporcionalidade entre inputs e outputs. O modelo BCC (ou VRS, de variable returns to scale), proposto por Banker et al. (1984), considera retornos variáveis de escala; substitui o axioma da proporcionalidade pelo axioma da convexidade.

Tradicionalmente são possíveis duas orientações radiais para esses modelos: orientação a inputs, quando é desejado minimizar os recursos disponíveis, sem alteração do nível de produção; orientação a outputs, quando o objetivo é aumentar os produtos, sem mudar a quantidade de recursos.

Existem duas formulações equivalentes para DEA. De forma simplificada pode-se dizer que a formulação conhecida como modelo dos Multiplicadores trabalha com a razão de somas ponderadas de produtos e recursos, com a ponderação escolhida de forma mais favorável a cada DMU, respeitando-se determinadas condições (ou seja, cada DMU é auto avaliada). A outra formulação, chamada de modelo do 
Envelope, define uma região viável de produção e trabalha com a projeção de cada DMU na fronteira dessa região. Uma vez que são duais, esses dois problemas calculam a mesma medida de eficiência.

Em (1) e em (2) apresentam-se, respectivamente, o modelo DEA CCR dos Multiplicadores e do Envelope, com orientação a inputs. Considera-se que cada DMU $k$, $k=1 \ldots n$, é uma unidade de produção que utiliza $m$ inputs $x_{i k}, i=1 \ldots m$, para produzir $s$ outputs $y_{j k}, j=1 \ldots$. Em ambas as formulações $h_{o}$ é a eficiência da DMU $o$ em análise; $x_{i o}$ e $y_{j o}$ são os inputs e outputs da DMU $o$. Em (1), $v_{i}$ e $u_{j}$ são os pesos calculados pelo modelo para inputs e outputs, respectivamente. Em (2), $\lambda_{k}$ representa a contribuição da DMU $k$ na formação do alvo da DMU $o$. A formulação matemática dos demais modelos DEA pode ser vista em Cooper et al. (2006).

$$
\begin{aligned}
& \operatorname{Max} h_{o}=\sum_{j=1}^{s} u_{j} y_{j o} \\
& \text { sujeito a } \\
& \sum_{i=1}^{m} v_{i} x_{i o}=1 \\
& -\sum_{i=1}^{m} v_{i} x_{i k}+\sum_{j=1}^{s} u_{j} y_{j k} \leq 0, \forall k \\
& u_{j}, v_{i} \geq 0, \forall j, i
\end{aligned}
$$

$$
\begin{aligned}
& \text { Min } h_{o} \\
& \text { sujeito a } \\
& h_{o} x_{i o}-\sum_{k=1}^{n} x_{i k} \lambda_{k} \geq 0, \forall i \\
& -y_{j o}+\sum_{k=1}^{n} y_{j k} \lambda_{k} \geq 0, \forall j \\
& \lambda_{k} \geq 0, \forall k
\end{aligned}
$$

\subsection{Uso de modelos DEA em agricultura}

O uso DEA para medir a eficiência relativa de unidades produtivas tem-se mostrado bastante atrativo em diversos setores de aplicação. O emprego de modelos DEA em agricultura pode vir a apoiar as decisões dos agricultores (e dos órgãos de fomento ou de associações de agricultores), ao indicar as fontes de ineficiência e as unidades que podem servir de referência às práticas adotadas (identificação de benchmarks).

Revisões sobre o estado da arte do uso de fronteiras de produção em agricultura podem ser vistas em Battese (1992), que apresenta aplicações de modelos de fronteiras paramétricas. Aplicações de métodos de fronteiras à agricultura de países em desenvolvimento são resumidas por Bravo-Ureta e Pinheiro (1993). Coelli (1995) completa o estudo desses autores e mostra que de 38 artigos encontrados sobre o tema "fronteiras de produção e avaliação de eficiência", somente três utilizavam DEA até aquela data (FÄRE et al., 1985; RAY, 1985; CHAVAS; ALIBER, 1993). Uma ampla revisão bibliográfica sobre o uso específico de modelos DEA em agricultura pode ser encontrada em Gomes (2008).

O uso de modelos DEA para avaliação em agricultura no Brasil pode ser encontrado, entre outros, em Toresan (1998), Pereira et al. (2002), Tupy e Yamagushi (2002), Gomes e Mangabeira (2004) e Gomes et al. (2005a, 2005b, 2009).

Para o caso específico de Machadinho d'Oeste, Gomes et al. (2005b) e Valladares et al. (2006) estudaram a relação espacial entre fertilidade do solo e eficiência técnica (medida com modelos DEA) para os dados da pesquisa de campo conduzida em 1999. As medidas de eficiência foram espacializadas e as eficiências e ineficiências foram explicadas a partir de características espaciais, não inseridas no modelo. Modelos DEA e multicritério também foram aplicados aos agricultores de Machadinho d'Oeste, com o objetivo de avaliar o bem-estar social rural (GOMES et al., 2008) e a sustentabilidade da agricultura da região (GOMES et al., 2009).

\section{ANÁLISE GEOESTATÍSTICA}

Os dados de eficiência dos quatro anos avaliados (1989, 1996, 1999 e 2002) foram inicialmente analisados pela estatística descritiva exploratória, calculando-se média, variância, coeficiente de variação, valores extremos - mínimos e máximos -, e coeficientes indicativos de distribuição normal de frequências - assimetria e curtose. Com essa análise visou-se a detecção de valores discrepantes e a distribuição de frequência dos dados.

Para a análise geoestatística, considerada a hipótese de autocorrelação ou dependência espacial entre os dados georreferenciados, segundo Vieira (2000), foram construídos e ajustados os semivariogramas obtidos pela representação gráfica da semivariância com a distância, conforme equação (3).

$$
\gamma(h)=\frac{1}{2 N(h)} \sum_{i=1}^{N}\left[Z\left(x_{i}\right)-Z\left(x_{i}+h\right)\right]^{2}
$$

Em (3), $N(h)$ é o número de pares de valores $Z\left(x_{i}\right)$ e $Z\left(x_{i}+h\right)$ separados por um vetor $h$. Pela equação (3) tem-se que à medida que a distância entre os pares é diminuída em direção a zero, espera-se uma redução da diferença entre os pares. 
Segundo Druck et al. (2004), o primeiro valor de semivariância calculado, $\gamma(h)$, é denominado "efeito pepita" (Co) e representa a variabilidade em distâncias menores do que aquelas amostradas. A dependência espacial existe quando há aumento da semivariância até determinada distância, denominada "alcance" (a), que é a distância dentro da qual as amostras encontram-se correlacionadas espacialmente. Após o alcance ocorre uma estabilização da semivariância em um valor denominado "patamar" $(\mathrm{Co}+\mathrm{C} 1)$, sendo que após este valor não existe mais dependência espacial entre as amostras. Para o caso dos dados deste artigo, todos os semivariogramas obtidos foram ajustados ao modelo esférico. Segundo Vieira (2000), este é o modelo mais adotado em geoestatística.

A interpolação de valores, no campo de estudo, para variáveis dependentes espacialmente foi realizada com o método de "krigagem", descrito por Vieira (2000). Esta é uma técnica adotada na geoestatística para estimativa de valores de propriedades em locais ainda não avaliados. Para o seu uso adequado é necessário que haja a dependência espacial definida pelo semivariograma. Segundo Druck et al. (2004), a krigagem é um processo para estimativa de valores de propriedades espacialmente distribuídas, a partir de valores adjacentes interdependentes, onde o procedimento é semelhante ao de interpolação por média móvel ponderada. Nesta abordagem, os pesos são determinados pela análise espacial baseada no semivariograma experimental, fornecendo em média estimativas não tendenciosas e com variância mínima.

Para as análises de estatística descritiva e semivariograma foram utilizados os programas desenvolvidos por Vieira et al. (2002). A interpolação de dados por krigagem ordinária e a espacialização em mapas de isolinhas foram elaboradas no programa ArcMap 8.3 (ESRI, 2002).

\section{MODELAGEM}

A estruturação de um modelo DEA necessita da definição das variáveis a constituir o modelo (inputs e outputs), das unidades a avaliar e do modelo DEA adotado (CCR, BCC, entre outros; orientação a inputs, a outputs etc.).

A etapa de seleção das variáveis é de grande importância, pois dela depende a qualidade dos resultados. Um modelo com grande número de variáveis pode acarretar uma avaliação extremamente benevolente, com várias DMUs 100\% eficientes. Porém, a seleção não deve levar em conta apenas aspectos quantitativos: devido às características dos modelos DEA, é essencial que haja uma relação causal entre cada par input-output do modelo. Deve-se observar ainda que a seleção de variáveis representa uma escolha que determina o que o modelo irá medir.

Para este caso de avaliação do desempenho no uso da terra foram selecionadas quatro variáveis coletadas no questionário de campo em Machadinho d'Oeste. Essas variáveis indicam as relações da produtividade da terra (relação produçãoárea), em unidades físicas de medida. $\mathrm{O}$ uso de medidas físicas ao invés de monetárias para a produção justifica-se, já que a obtenção de preços confiáveis é difícil para a região e seu uso poderia mascarar a eficiência produtiva com erros de medidas de preços e oscilações de mercado. Além disso, o uso de preços pode mascarar relações de eficiência ou ineficiência, e modelos DEA são particularmente úteis quando os aspectos financeiros não são os mais relevantes ou quando não se deseja levá-los em conta (SOARES DE MELLO et al., 2003). Para uma discussão sobre o uso de séries históricas de preços, ver, por exemplo, Pereira et al. (2002).

\section{A ausência de relação causal entre pares de inputs e outputs pode ser considerada uma armadilha em modelagem DEA.}

Cabe destacar que, conforme descrito em Coelli et al. (2005), a disponibilidade de dados sobre preços e da imposição de uma hipótese de minimização de custos ou maximização de lucros conduzem ao conceito de eficiência alocativa, em adição às medidas de eficiência técnica. Ainda, a combinação das medidas de eficiência técnica e alocativa leva ao conceito de eficiência econômica. Färe et al. (2004) abordam essas questões com o uso de funções de distância direcionais.

De modo a obter resultados mais significativos, ao invés de usar as variáveis totais para cada lote foram selecionadas apenas as culturas mais significativas na região. De acordo com pesquisadores que atuam há mais de 20 anos no local, a única cultura perene de alguma expressão é o café, tanto pelo número de propriedades, quanto pela duração dos cultivos e existência de dados. As demais não são passíveis de análise, já que são culturas que demoram a entrar em produção, as estimativas de colheita são irregulares etc.

Para as culturas anuais, as de maior importância são arroz e milho. No geral, as culturas anuais alteram-se bastante em Machadinho, pela oscilação dos preços, do clima e pela opção de serem plantadas intercaladas entres as culturas perenes.

Algumas outras culturas são cultivadas na região, como mandioca, feijão, cacau, frutas, hortaliças e seringueira. No 
entanto, a sua importância econômica é pequena (MIRANDA, 2005). A inclusão de algumas dessas culturas como output poderia distorcer os resultados do modelo. No caso extremo de apenas um agricultor produzir uma dessas culturas, ele seria eficiente sem considerar as culturas mais importantes economicamente.

A opção aqui feita representa o que a maioria dos lotes produzem em Machadinho d'Oeste: uma cultura de renda, que é o café, e uma ou duas culturas alimentares para autoconsumo e eventual venda de excedentes. A venda de excedentes de produção é feita para os cerealistas locais, já que vender em outros mercados torna-se inviável devido aos altos custos do transporte da mercadoria, em função da distância e das condições inadequadas de tráfego nas estradas. A produção simultânea de diversas culturas mostra-se como uma dificuldade de produção local, em especial pela limitação da mão-de-obra.

Uma preocupação que deve estar sempre presente nos modelos DEA é a existência de relação causal entre inputs e outputs. Esta relação causal é uma das bases dos métodos automáticos de seleção de variáveis (ANGULO MEZA et al., 2007; COOK e ZHU, 2007; SENRA et al., 2007; WAGNER e SHIMSHAK, 2007; LINS; MOREIRA, 1999). Da mesma forma, a escolha de variáveis pela opinião de especialistas deve levar em conta esta relação causal. A ausência de relação causal entre pares de inputs e outputs pode ser considerada uma armadilha em modelagem DEA. Ver Dyson et al. (2001) para um estudo sobre armadilhas em DEA. Assim, as variáveis do modelo DEA são área cultivada de milho, de arroz e de café (soma das áreas parciais) como input único, e produção de milho, produção de arroz e produção de café como outputs.

Algumas observações devem ser feitas em relação a este modelo. Em primeiro lugar, como DEA permite trabalhar com múltiplos inputs e outputs, pode-se questionar a razão de usar a área total plantada ao invés de cada uma das áreas parciais. O que surge é que se fosse feita essa escolha por variáveis parciais, poderia acontecer de uma propriedade ser eficiente por apresentar a melhor relação entre produção de uma cultura e área plantada de outra, o que seria, evidentemente, um absurdo. Embora a situação extrema aqui relatada possa ser mitigada com técnicas como a adição de restrições aos pesos, a ausência de relação causal entre qualquer par output-input pode causar distorções no modelo (ver, por exemplo, SILVEIRA et al., 2008).

Em segundo lugar, é necessário interpretar o que significa uma propriedade ser eficiente. Devido à característica benevolente de DEA é eficiente quem conseguir a melhor relação entre a produção de uma cultura e a área cultivada total (das três culturas consideradas). Ou seja, o modelo permite que propriedades especializadas em uma das culturas sejam eficientes. Entretanto, considera também como eficientes propriedades que consigam um bom arranjo de produção combinada. Tem-se, assim, a vantagem de não penalizar a avaliação dos agricultores em razão das escolhas feitas em relação ao que produzir. Um modelo alternativo, não contemplado neste estudo, seria desagregar a alocação de terras para cada cultura e considerar um índice agregado de produção, semelhante ao usado em Pereira et al. (2002). A desagregação simultânea de outputs e inputs incorreria no já citado problema de falta de relação causal, como mostrado em Gomes et al. (2009).

As DMUs do modelo DEA são os produtores rurais amostrados, que foram entrevistados pelas pesquisas de campo em 1989, 1996, 1999 e 2002 (um modelo DEA para cada ano), e que produziram pelo menos uma das três culturas em cada um desses anos.

Quanto à escolha do modelo DEA, pesquisas recentes (HOLLINGSWORTH; SMITH, 2003) mostram que o modelo DEA BCC tem relação com a falta de proporcionalidade entre inputs e outputs, e não com retornos de escala. Face a essa questão, preferiu-se optar neste artigo pelo modelo CCR. Como é desejado verificar se a produção justifica a quantidade de recursos empregados, foi usada orientação a inputs.

\section{RESULTADOS}

\subsection{Medidas de eficiência}

Para a avaliação da produtividade da terra com emprego de modelos DEA, consideraram-se todos os agricultores que produziram pelo menos uma das culturas (arroz, milho ou café) em cada um dos quatro anos avaliados. O número total de agricultores (DMUs) em cada modelo DEA foi de 341, 299, 319 e 188 para 1989, 1996, 1999 e 2002, respectivamente.

A Tabela 1 traz um resumo das características de cada conjunto de dados em cada ano. Nessa tabela, frequência relativa refere-se, em cada ano, à relação entre o número de agricultores que produziram determinada cultura e o número total de agricultores (que produziram pelo menos uma das culturas).

Nota-se o aumento da importância da cultura agroindustrial do café, produzido quase em sua totalidade sem uso de insumos, e a redução das culturas alimentares na região. Conforme destacado em Mangabeira et al. (2005), o café, junto com a pecuária, é a principal fonte de renda dessas famílias. As culturas alimentares limitam-se ao autoconsumo e, em geral, não geram excedente significativo para comercialização. No caso do milho, este é também usado como ração para os animais. Esses fatos justificariam a ex- 
pansão do café e a contração sofrida pelas culturas anuais, que diminuem de importância agronômica e financeira em Machadinho d'Oeste.

Na Tabela 2 encontram-se as medidas de eficiência dos modelos DEA, calculadas com o software SIAD (ANGULO MEZA et al., 2005). As colunas A a $G$ indicam as combinações de culturas praticadas. Nessa tabela, frequência relativa refere-se, em cada ano, à relação entre o número de agricultores que produziram determinada cultura e o número total de agricultores.

Para o ano de 1989 na Tabela 2, por exemplo, ao analisarem-se somente os lotes com produção de arroz, estes representavam $24,9 \%$ do total ( 85 em 341 lotes). Para esses, a eficiência no uso da terra foi, em média, de $20,4 \%$, sendo que um dos 85 produtores foi considerado DEA CCR eficiente. Deve-se ressaltar que a frequência relativa está relacionada apenas ao número de propriedades e não ao seu tamanho. Assim, não cabem quaisquer considerações sobre escala de operação das unidades e das culturas.

Verifica-se, no geral, que a eficiência média em Machadinho d'Oeste, ao considerar produção e área, é baixa. Entretanto, deve ser ressaltado que isto não significa necessariamente uma baixa produtividade dos agricultores da região, assim como alta produtividade não significaria o contrário. Os agricultores foram comparados apenas em relação a eles próprios e, portanto, a baixa eficiência média significa apenas uma grande falta de homogeneidade nas produtividades ou, devido às características de busca pela excelência de DEA, a existência de uma propriedade ou de um pequeno número delas muito produtivas.

Em termos relativos, o café foi, dentre as três culturas,

Tabela 1: Características dos grupos analisados, segundo o ano de estudo e o tipo de cultura.

\begin{tabular}{ccccc}
\hline & & Arroz & Café & Milho \\
\hline \multirow{2}{*}{1989} & Freq. relativa (\%) & 88,6 & 38,4 & 59,2 \\
& Área média (ha) & 4,1 & 5,2 & 2,6 \\
& Produção média (kg) & $4.055,7$ & $9.445,3$ & $2.631,2$ \\
\hline \multirow{2}{*}{1996} & Freq. relativa (\%) & 65,2 & 78,9 & 55,2 \\
& Área média (ha) & 2,8 & 7,1 & 2,8 \\
& Produção média (kg) & $2.080,0$ & $4.384,9$ & $6.145,0$ \\
\hline \multirow{2}{*}{1999} & Freq. relativa (\%) & 53,3 & 90,3 & 46,4 \\
& Área média (ha) & 2,5 & 6,4 & 2,3 \\
& Produção média (kg) & $2.280,6$ & $1.830,8$ & $2.365,5$ \\
\hline \multirow{2}{*}{2002} & Freq. relativa (\%) & 38,8 & 94,7 & 37,2 \\
& Área média (ha) & 2,2 & 7,2 & 2,1 \\
& Produção média (kg) & $1.874,5$ & $5.177,1$ & $2.055,1$ \\
\hline
\end{tabular}

a que mais cresceu na região, em relação ao percentual de agricultores que o cultivam. Conforme anteriormente destacado, isto se deve à sua importância econômica para a região. Adicionalmente, a maioria dos produtores é proveniente de regiões produtoras de café e levaram o conhecimento dessa prática agrícola para Machadinho d'Oeste. Entretanto, a eficiência daqueles que cultivam café (seja somente o café ou com arroz e/ou milho) é menor quando comparada com a eficiência obtida pelos agricultores que produzem arroz e/ ou milho. Essa situação poderia ser alterada pelo crédito para investimentos, que seria relevante para melhorar determinados sistemas e estruturas de produção, frente a atividades de maior impacto. Por exemplo, conforme destacado em Mangabeira et al. (2005), o fortalecimento das culturas perenes e dos sistemas agroflorestais passa pela construção de terreiros suspensos (o que melhoraria a secagem e a qualidade do café), tulhas, entre outros.

Outra questão que pode melhorar a eficiência daqueles que produzem café é a prática de sombreamento com árvores nativas, pela qual o solo fica quase ou totalmente recoberto pela vegetação, protegido das chuvas e da incidência direta dos raios solares. Em 2002, cerca de 30\% dos produtores já sombreavam o café e essa prática tem provado ter influência sobre o aumento da produtividade (pela uniformidade de produção entre os anos, já que diminui o efeito bianual de safras altas e baixas), sobre a diminuição de pragas e doenças e sobre a restauração/manutenção de alguns nutrientes nos solos (MANGABEIRA et al., 2005).

Para a cultura do arroz em 1989, 1996, 1999 e 2002, a de milho em 2002 e a de café em 1996, 1999 e 2002 foram encontrados produtores DEA CCR eficientes. Estes foram aqueles que obtiveram a melhor relação entre a produção de arroz, milho ou café e a área cultivada dessas culturas (já que eram as únicas, dentre as três, que produziam). Estes produtores podem servir de referência para seus pares ou para órgãos de assistência técnica, na identificação e caracterização de práticas de bom uso da terra.

A cultura do milho não é eficiente quando não produzida junto com as culturas do arroz e/ou café. Apenas um agricultor desse tipo consegue eficiência e, mesmo assim, só em 2002. Ela mostra-se mais eficiente quando associada com a cultura do arroz.

Em relação aos resultados do modelo dos multiplicadores nota-se que a distribuição de pesos zero foi maior para a produção de café somente em 1989 (62\% das DMUs). Nessa época, a produção de café era incipiente na região, ou seja, as mudas que haviam sido plantadas nos anos anteriores estavam em início de produção. Ressalta-se que, em 2002, as plantas de café tinham em média oito anos (MANGABEIRA et al., 2005). Nos demais anos, em média 12\% das DMUs atri- 
buíram peso zero a essa cultura. Em contrapartida, a cultura do arroz teve, em 1989, 14\% de pesos zero; nos demais anos esse percentual atingiu a média de $50 \%$. A cultura do milho apresentou uma média de $55 \%$ de pesos zero nos quatro anos. Isto se deve à própria estrutura do modelo, já que, na maior parte dos casos, o modelo atribuiu peso zero àquela cultura que não foi produzida naquele ano. Deve-se ressaltar que esses foram apenas os primeiros pesos encontrados pelo software de DEA usado. Não foram examinados todos de eficiência em variação da tecnologia e variação de cada DMU. Já as janelas de tempo são usadas quando se deseja medir apenas a variação de eficiência de cada DMU, sem considerar as variações de tecnologia. Asmild et al. (2004) propuseram a combinação destas duas técnicas de avaliação temporal em DEA.

Dada a pouca introdução de novas tecnologias de produção ao longo do tempo em Machadinho d'Oeste, neste artigo foi feita uma adaptação do modelo de janelas de tempo. Aqui foi considerado que cada ano corresponde a uma janela. Assim, um mesmo produtor em dois anos diferentes é tratado como uma DMU diferente, em abordagem idêntica à de Soares de Mello et al. (2003), Rios os possíveis ótimos alternativos (ROSEN et al., 1998) nem usada nenhuma técnica de escolha de um dos possíveis pesos (COOPER et al., 2007; SOARES DE MELLO et al., 2002, 2004). Para evitar pesos nulos poderiam ser usados modelos não arquimedeanos (COOPER et al., 2006). No entanto, o efeito do resultado desses modelos nos valores das medidas de eficiência seria infinitesimal.

\subsection{Evolução temporal}

Para avaliar as tendências de variação das medidas de eficiência ao longo do tempo existem duas técnicas principais: 0 índice de Malmquist (FÄRE et al., 1994) e as janelas de tempo (TULKENS; VANDEN EECKAUT, 1995). O índice de Malmquist é usado quando se deseja decompor a avaliação e Maçada (2006) e Gomes et al. (2009). Esta mesma técnica pode ser usada quando é necessário aumentar o número de DMUs na análise, conforme Podinovski e Thanassoulis (2007). Ressalte-se que este não é o caso no estudo aqui em apreço.

Os resultados desse modelo são apresentados na Tabela 3. Verifica-se que a melhor eficiência é obtida pela combinação de produção de arroz e milho. Entre os que optam pela monocultura, destaca-se a baixa eficiência dos produtores de café. Em qualquer combinação com a cultura de café a eficiência é baixa, mas maior que a da monocultura de café.

Note-se que, apesar de a eficiência média dos produtores de café ser baixa, em cada ano há DMUs produtoras de café eficientes, como observado na Tabela 2. Evidentemente, es-

Tabela 2: Resultados do modelo DEA.

\begin{tabular}{|c|c|c|c|c|c|c|c|c|c|}
\hline & & $A$ & $B$ & $\mathrm{C}$ & $\mathrm{D}$ & $E$ & $\mathrm{~F}$ & $\mathrm{G}$ & \\
\hline & & Arroz & Arroz e Café & $\begin{array}{c}\text { Arroz e } \\
\text { Milho }\end{array}$ & $\begin{array}{c}\text { Arroz, Café e } \\
\text { Milho }\end{array}$ & Café & Milho & Café e Milho & Global \\
\hline \multirow[t]{3}{*}{1989} & Efic. média (\%) & 20,4 & 18,5 & 21,9 & 21,9 & 21,6 & 20,2 & 29,0 & 21,3 \\
\hline & Freq. relativa (\%) & 24,9 & 9,4 & 33,7 & 20,5 & 6,5 & 2,9 & 2,1 & 100,0 \\
\hline & DMUs eficientes & 1 & 1 & - & 1 & - & - & - & 3 \\
\hline \multirow[t]{3}{*}{1996} & Efic. média (\%) & 41,3 & 33,2 & 41,9 & 28,2 & 21,9 & 38,0 & 31,9 & 30,4 \\
\hline & Freq. relativa (\%) & 6,4 & 14,4 & 11,0 & 33,4 & 24,1 & 3,7 & 7,0 & 100,0 \\
\hline & DMUs eficientes & 1 & - & 2 & - & 1 & - & - & 4 \\
\hline \multirow[t]{3}{*}{1999} & Efic. média (\%) & 54,2 & 30,8 & 62,6 & 32,6 & 16,2 & 25,2 & 42,6 & 28,2 \\
\hline & Freq. relativa (\%) & 5,0 & 15,7 & 3,1 & 29,5 & 32,9 & 1,6 & 12,2 & 100,0 \\
\hline & DMUs eficientes & 1 & - & 1 & - & 1 & - & - & 3 \\
\hline \multirow[t]{3}{*}{2002} & Efic. média (\%) & 53,6 & 22,7 & 77,2 & 35,6 & 14,3 & 53,9 & 30,8 & 24,4 \\
\hline & Freq. relativa (\%) & 2,1 & 9,0 & 1,6 & 26,1 & 51,6 & 1,6 & 8,0 & 100,0 \\
\hline & DMUs eficientes & 1 & - & 1 & 1 & 1 & 1 & - & 5 \\
\hline
\end{tabular}


tes agricultores podem servir de benchmark para os demais produtores de café.

Por outro lado, o quantitativo de agricultores que produzem café isoladamente ou em conjunto com outras culturas tem aumentado ao longo do tempo.

Há duas possíveis explicações para esta aparente contradição (redução de eficiência X aumento do número de produtores). A primeira é que os agricultores da região estão mal orientados em relação aos seus cultivos. A segunda está relacionada com o fato de o modelo DEA aqui usado levar em conta apenas a eficiência no uso da terra. Variáveis ligadas a preços e mercados de forma geral não foram aqui consideradas. Assim, a cultura do café, embora não eficiente, pode ser atrativa financeiramente, visto que esta é a principal cultura de renda da região. São necessários estudos adicionais para confirmar ou não estas hipóteses, os quais estão fora da proposta deste artigo.

Na Tabela 4 apresentam-se as frequências relativas referentes às faixas de eficiência. Nesta tabela os valores referem-se ao percentual de produtores que tiveram valor de eficiência em certa faixa, categorizados por seus arranjos produtivos. É ainda mostrado o número total de agricultores em cada arranjo produtivo (linha "Frequência absoluta total"). Os resultados desta tabela mostram que há um grande número de produtores ineficientes, independentemente do arranjo produtivo de cada um.

A Tabela 5 mostra a evolução das três DMUs que foram eficientes no modelo de avaliação temporal. A propriedade A, eficiente em 1989, trocou de proprietário entre 1989 e 1996 e não teve mais sua eficiência calculada pelo modelo aqui usado, por passar a dedicar-se a outros tipos de exploração da terra.

O agricultor B tem sua eficiência decrescente a partir de 1996. Entre 1989 e 1996 houve mudança de proprietário e de política produtiva neste lote, com a crescente dedicação à cultura do café. A eficiência decrescente neste caso está de acordo com os valores médios observados em parágrafos anteriores.

Já o lote $\mathrm{C}$ teve sempre o mesmo proprietário e sempre produziu café. Tem eficiência crescente, desde que não se considere o ano de 1996, para o qual não há dados declarados. Este é um benchmark para os produtores de café e suas práticas devem ser melhor estudadas em futuros trabalhos de campo.

A verificação de quais fatores influenciam na eficiência requer um trabalho de campo que levante dados sobre variáveis agrícolas e sociais, não inclusas nos questionários aqui usados. Tal fato impossibilita aqui este tipo de análise. Um estudo deste tipo usando testes não paramétricos para um modelo diferente e variáveis contextuais de caráter social foi desenvolvido por Gomes et al. (2009). Naquele caso uma das variáveis explicativas mais importantes era a regularização da posse da terra.

\section{Nos dois últimos anos avaliados (1999 e 2002) houve maior uniformização em termos da eficiência produtiva dos lotes.}

\subsection{Variabilidade espacial das medidas de eficiência}

Para a análise de variabilidade espacial, as medidas de eficiência foram inicialmente analisadas pela estatística descritiva exploratória, com o cálculo de média, variância, coeficiente de variação, valores extremos (mínimos e máximos) e coeficientes indicativos de distribuição de frequências ( simetria e curtose). Com essa análise detectaram-se valores discrepantes da distribuição de frequência dos dados (mínimo 0,005 e máximo 1,000), conforme Tabela 6, apresentando valores de simetria e curtose diferentes de zero. Isto indica distribuição de frequência log normal. Neste caso, o valor de tendência central média difere da moda e da mediana, o que pode interferir na análise de dependência espacial estruturada no semivariograma. Os altos valores encontrados para o coeficiente de variação reforçam ainda mais esta

Tabela 3: Eficiência média (\%) com modelo temporal.

\begin{tabular}{cccccccc}
\hline & Arroz & Arroz e Café & $\begin{array}{c}\text { Arroz } \\
\text { e Milho }\end{array}$ & $\begin{array}{c}\text { Arroz, Café } \\
\text { e Milho }\end{array}$ & Café & $\begin{array}{c}\text { Milho } \\
\text { e Milho }\end{array}$ \\
\hline 1989 & 20,4 & 13,9 & 21,9 & 17,6 & 10,1 & 20,4 & 15,8 \\
1996 & 15,5 & 13,7 & 23,7 & 15,0 & 10,0 & 19,5 & 15,5 \\
1999 & 17,6 & 10,2 & 26,1 & 12,2 & 5,5 & 17,5 & 13,5 \\
2002 & 16,1 & 15,6 & 24,5 & 17,6 & 14,3 & 15,5 & 17,3 \\
Média & 17,4 & 13,4 & 24,1 & 15,6 & 10,0 & 14,1 \\
\hline
\end{tabular}


discrepância e anormalidade entre os dados.

Os semivariogramas de 1989, 1999 e 2002 mostraram a existência de dependência espacial, ou seja, um crescimento da semivariância em função da distância (Figura 1a, 1d e 1e, respectivamente), iniciado em Co (efeito pepita) até um certo alcance $(\mathrm{a})$, atingindo o patamar $(\mathrm{Co}+\mathrm{C} 1)$, conforme descrito em Vieira (2000) e Druck et al. (2004), sem a necessidade prévia de transformação.

A eficiência de 1996 inicialmente não mostrou dependência espacial, ou seja, ocorreu efeito pepita puro, o que indica aleatoriedade entre os dados, não permitindo o ajuste do semivariograma a uma função. Estes dados são mostrados

Tabela 4: Frequências relativas (\%) por arranjo produtivo e faixa de eficiência no modelo temporal.

\begin{tabular}{|c|c|c|c|c|c|c|c|c|}
\hline Ano & Faixa de eficiência & Arroz & $\begin{array}{l}\text { Arroz } \\
\text { e Café }\end{array}$ & $\begin{array}{c}\text { Arroz } \\
\text { e Milho }\end{array}$ & $\begin{array}{c}\text { Arroz, Café } \\
\text { e Milho }\end{array}$ & Café & Milho & $\begin{array}{c}\text { Café } \\
\text { e Milho }\end{array}$ \\
\hline \multirow[t]{5}{*}{1989} & $0-25 \%$ & 74,1 & 90,6 & 61,7 & 80,0 & 90,9 & 80,0 & 85,7 \\
\hline & $25 \%-50 \%$ & 22,3 & 6,3 & 38,3 & 18,6 & 9,1 & 0,0 & 14,3 \\
\hline & $50 \%-75 \%$ & 2,4 & 3,1 & 0,0 & 1,4 & 0,0 & 10,0 & 0,0 \\
\hline & $75 \%-100 \%$ & 1,2 & 0,0 & 0,0 & 0,0 & 0,0 & 10,0 & 0,0 \\
\hline & Frequência absoluta total & 85 & 32 & 115 & 70 & 22 & 10 & 7 \\
\hline \multirow[t]{5}{*}{1996} & $0-25 \%$ & 94,7 & 90,7 & 75,8 & 91,0 & 97,2 & 81,8 & 90,5 \\
\hline & $25 \%-50 \%$ & 5,3 & 9,3 & 18,2 & 8,0 & 2,8 & 18,2 & 9,5 \\
\hline & $50 \%-75 \%$ & 0,0 & 0,0 & 3,0 & 1,0 & 0,0 & 0,0 & 0,0 \\
\hline & $75 \%-100 \%$ & 0,0 & 0,0 & 3,0 & 0,0 & 0,0 & 0,0 & 0,0 \\
\hline & Frequência absoluta total & 19 & 43 & 33 & 100 & 72 & 11 & 21 \\
\hline \multirow[t]{5}{*}{1999} & $0-25 \%$ & 87,5 & 98,0 & 70,0 & 95,7 & 98,1 & 100,0 & 97,4 \\
\hline & $25 \%-50 \%$ & 12,5 & 2,0 & 30,0 & 4,3 & 1,9 & 0,0 & 2,6 \\
\hline & $50 \%-75 \%$ & 0,0 & 0,0 & 0,0 & 0,0 & 0,0 & 0,0 & 0,0 \\
\hline & $75 \%-100 \%$ & 0,0 & 0,0 & 0,0 & 0,0 & 0,0 & 0,0 & 0,0 \\
\hline & Frequência absoluta total & 16 & 50 & 10 & 94 & 105 & 5 & 39 \\
\hline \multirow[t]{5}{*}{2002} & $0-25 \%$ & 75,0 & 100,0 & 100,0 & 91,8 & 87,6 & 100,0 & 86,7 \\
\hline & $25 \%-50 \%$ & 25,0 & 0,0 & 0,0 & 6,2 & 8,3 & 0,0 & 13,3 \\
\hline & $50 \%-75 \%$ & 0,0 & 0,0 & 0,0 & 0,0 & 3,1 & 0,0 & 0,0 \\
\hline & $75 \%-100 \%$ & 0,0 & 0,0 & 0,0 & 2,0 & 1,0 & 0,0 & 0,0 \\
\hline & Frequência absoluta total & 4 & 17 & 3 & 49 & 97 & 3 & 15 \\
\hline
\end{tabular}

Tabela 5: DMUs eficientes no modelo de avaliação temporal.

\begin{tabular}{|c|c|c|c|c|}
\hline & & A & $\mathrm{B}$ & $\mathrm{C}$ \\
\hline \multirow[t]{2}{*}{1989} & Eficiência (\%) & 100,0 & 100,0 & 20,7 \\
\hline & Culturas & Arroz & Milho & Arroz, Café e Milho \\
\hline \multirow[t]{2}{*}{1996} & Eficiência (\%) & - & 23,6 & - \\
\hline & Culturas & Extrativismo & Arroz, Café e Milho & Não declarado \\
\hline \multirow[t]{2}{*}{1999} & Eficiência (\%) & - & 2,9 & 27,6 \\
\hline & Culturas & Extrativismo & Arroz e Café & Arroz, Café e Milho \\
\hline \multirow[t]{2}{*}{2002} & Eficiência (\%) & - & 6,8 & 100,0 \\
\hline & Culturas & Extrativismo & Café & Café \\
\hline
\end{tabular}


Tabela 6: Parâmetros estatísticos das medidas de eficiência.

\begin{tabular}{ccccc}
\hline & 1989 & 1996 & 1999 & 2002 \\
\hline N. ${ }^{0}$ de pontos & 338 & 286 & 311 & 185 \\
Média & 0,213 & 0,299 & 0,295 & 0,245 \\
V & 0,024 & 0,033 & 0,045 & 0,046 \\
DP & 0,154 & 0,181 & 0,212 & 0,215 \\
CV (\%) & 72,25 & 60,58 & 74,23 & 87,54 \\
Min & 0,008 & 0,030 & 0,011 & 0,005 \\
Max & 1,000 & 1,000 & 1,000 & 1,000 \\
Simetria & 2,167 & 1,314 & 1,162 & 1,671 \\
Curtose & 7,934 & 2,593 & 1,177 & 3,041 \\
\hline
\end{tabular}

na Figura 1b, sem curva de ajuste. Isto pode ter ocorrido também devido a valores extremos estarem localizados a pequenas distâncias e à ocorrência de anormalidade na distribuição de frequência dos dados. Utilizando a transformação logaritmo nos dados de 1996, foi possível o ajuste esférico ao semivariograma, conforme Figura 1c.

Após a verificação da existência de dependência espacial através do ajuste do semivariograma foi realizada a interpolação de dados nos locais não amostrados pelo método da krigagem e a espacialização, resultando nos mapas de isolinhas, conforme Figura 2.

Ao analisar os dois primeiros anos, 1989 e 1996, comparativamente (Figuras 2a e 2b), a espacialização mostra-se

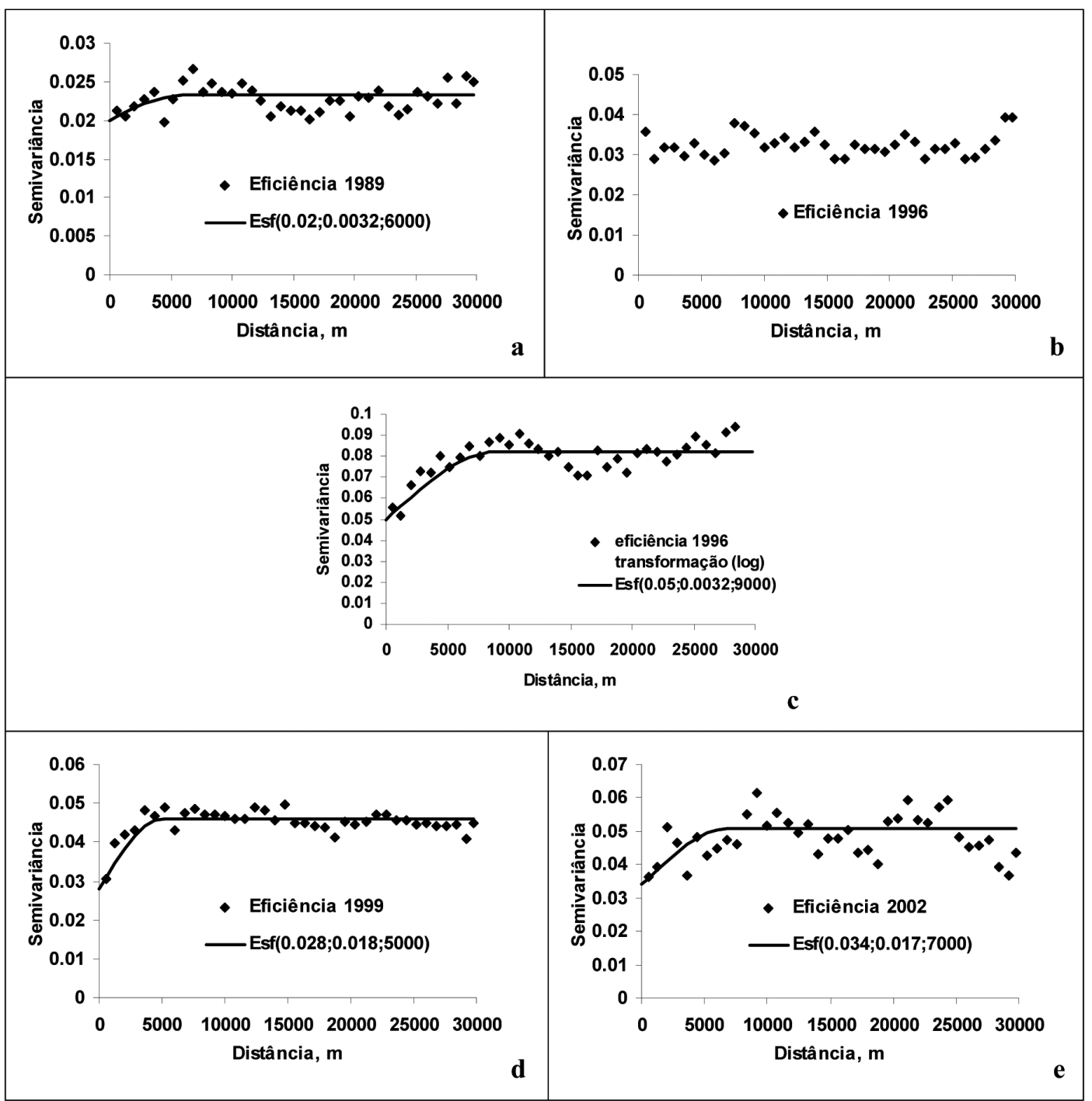

Figura 1: Semivariogramas ajustados pelo modelo esférico. 
praticamente contrária, pois os lotes mais eficientes no primeiro momento são os menos eficientes no segundo momento avaliado. Isto tanto pode ser devido ao emprego de técnicas para a melhoria do sistema produtivo, quanto ao aumento de área plantada adotada pelos produtores mais eficientes de 1996, localizados principalmente na parte superior da área.
Na parte superior, ao norte da área, segundo levantamento de solos feito por Valladares et al. (2003), ocorre predominância de solos em relevo plano e suave ondulado, refletindo na localização de maior eficiência produtiva em 1996. Contudo, de acordo com Gomes et al. (2007), ao norte da área ocorreu predominância de solos com baixa fertilidade, principalmente quanto à soma de bases e à saturação

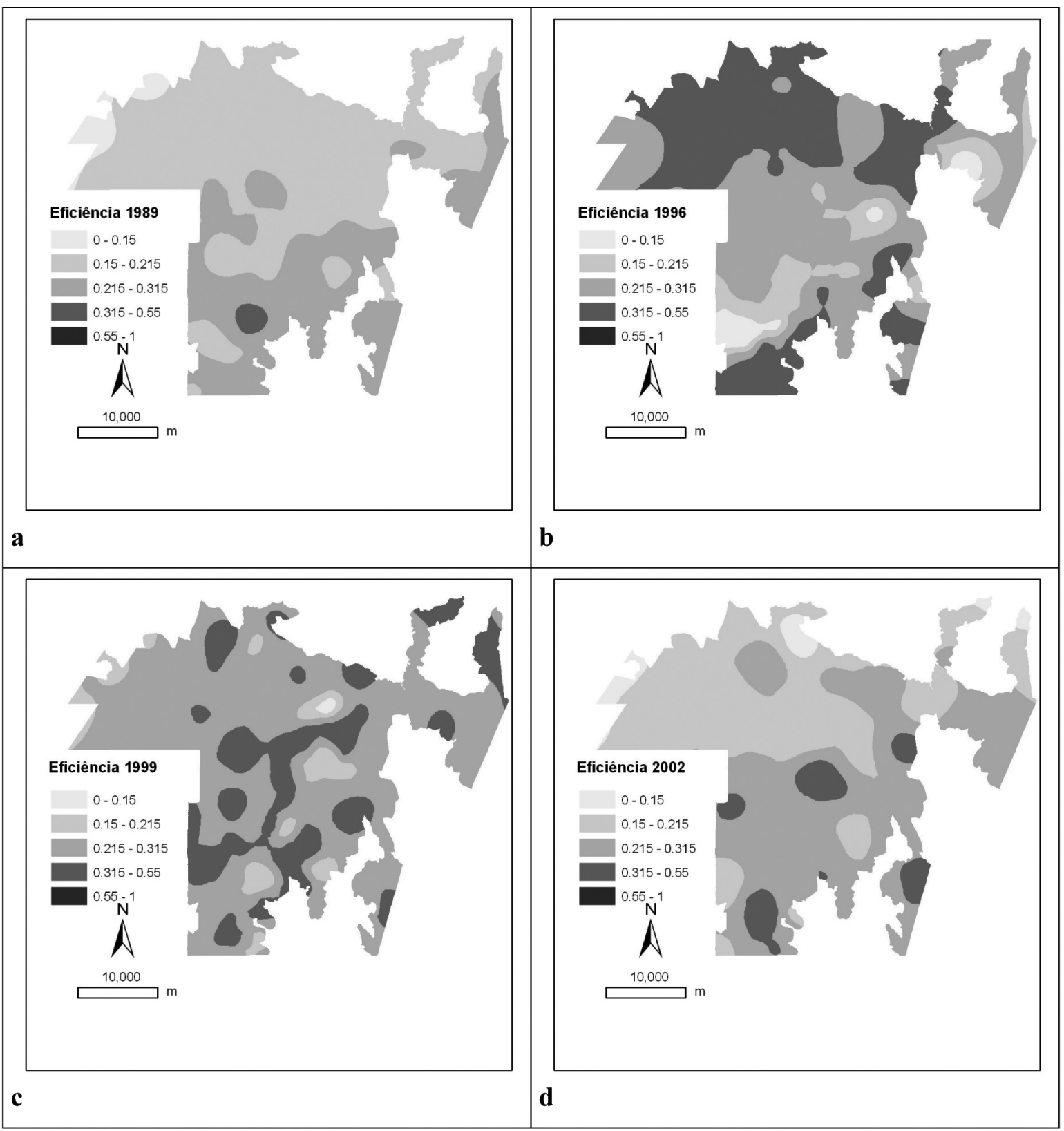

Figura 2: Mapas de isolinhas das medidas de eficiência para os anos de 1989 (a), 1996 (b), 1999 (c) e 2002 (d). 
por bases, o que pode ter levado à não permanência de alta eficiência nestes mesmos lotes ao longo dos anos que se seguem (1999 e 2002). Nos dois últimos anos avaliados (Figuras 2 c e 2d) observa-se maior uniformização em termos dos produtores mais eficientes, que deixaram de se concentrar na parte superior, diluindo-se por toda área, com sutil aglomeração central. Adicionalmente, as manchas de dependência espacial foram reduzidas, mostrando um encaminhamento para uniformização da eficiência produtiva dos lotes por toda área de estudo.

\section{CONCLUSÕES}

Os resultados mostram as diferenças de eficiência nos sistemas de produção agrícola praticados em Machadinho d'Oeste, nos diferentes anos de produção. Isto corrobora com o sentimento de que esses agricultores familiares, por falta de opção, financiamento, pouca assistência técnica e pesquisas apropriadas, estão "sozinhos" para produzir. Por outro lado, estes resultados podem direcionar os produtores menos eficientes, pela observação dos eficientes, na busca pela melhoria de seus sistemas de produção. Podem ainda servir de base para que pesquisadores e extencionistas locais apoiem o desenvolvimento desses produtores rurais de desempenho não satisfatório. Como verificado no estudo, há um grande número de agricultores com baixa eficiência, o que sugere a necessidade de aprimoramento e intensificação da assistência técnica.

A forte oscilação das medidas de eficiência pode ter várias razões, das quais três são aqui aventadas. A primeira pode ser devida à mudança de proprietário do lote, já que agri- cultores diferentes têm "racionalidades agrícolas" diferentes, e decisões de produção equivocadas podem influenciar o desempenho.

A segunda é por motivos agronômicos, em relação ao uso da terra. A produção em Machadinho d'Oeste é feita praticamente sem o uso de insumos externos. Quando as plantas do café ficam velhas e sem um manejo adequado de adubação verde (ou orgânica) ou reposição de outros nutrientes, o solo perde fertilidade ao longo do tempo, com consequente redução do desempenho produtivo. Para as culturas do arroz e do milho, quando plantadas sem consórcio (não no meio do café ou de outras culturas perenes), o manejo da capoeira pela queima e o tempo de pousio (ou descanso da terra) podem influenciar no desempenho futuro. Se este tempo de pousio for pequeno e as queimadas da capoeira forem frequentes, ocorrerá perda de fertilidade do solo, o que acarreta baixa produtividade da terra.

A terceira hipótese é ligada a fatores educacionais e ambientais: um alto desempenho em um ano pode produzir um relativo bem-estar e menos empenho no ano seguinte.

Houve dependência espacial para a eficiência produtiva nos quatro anos avaliados. O resultado da espacialização de 1989 foi contrário ao de 1996, pois lotes menos eficientes localizados na parte superior da área no primeiro momento foram os mais eficientes em 1996. A adoção de técnicas para a melhoria do sistema produtivo e o aumento de área plantada podem ter contribuído para este resultado. Nos dois últimos anos avaliados (1999 e 2002) houve maior uniformização em termos da eficiência produtiva dos lotes por toda área de estudo. A parte superior deixou de ser a mais eficiente, concentrando-se na parte central da área.

\section{Artigo recebido em 12/02/2007 Aprovado para publicação em 26/03/2009}

\section{REFERÊNCIAS}

ALVES, E. Medidas de produtividade: dilemas da agricultura familiar. Revista de Economia e Agronegócio, v. 1, n. 3, p. 421-439, 2003.

ANGULO MEZA, L.; BIONDI NETO, L.; SOARES DE MELLO, J. C. C. B.; GOMES, E. G. ISYDS Integrated System for Decision Support (SIAD - Sistema Integrado de Apoio à Decisão): A software package for data envelopment analysis. Pesquisa Operacional, v. 25, n. 3, p. 493-503, 2005.
ANGULO MEZA, L.; SOARES DE MELLO, J. C. C. B.; GOMES, E. G.; FERNANDES, A. J. S. Selecção de variáveis em DEA aplicada a uma análise do mercado de energia eléctrica. Investigação Operacional, v. 27, p. 21-36, 2007.

ASMILD, M.; PARADI, J. C.; AGGARWALL, V.; SCHAFFNIT, C. Combining DEA window analysis with the Malmquist index approach in a study of the Canadian banking industry. Journal of Productivity Analysis, v. 21, n. 1, p. 67-89, 2004.
BANKER, R. D.; CHARNES, A.; COOPER, W. W. Some models for estimating technical scale inefficiencies in data envelopment analysis. Management Science, v. 30, n. 9, p. 1078-1092, 1984.

BATISTELLA, M. Landscape change and landuse/land-cover dynamics in Rondônia, Brazilian Amazon. Ph.D. dissertations, Indiana University, Bloomington, Indiana, 399 p., 2001. 
BATISTELLA, M.; BRONDIZIO, E. S.; MORAN, E.F. Comparative analysis of landscape fragmentation in Rondônia, Brazilian Amazon. International Archives of Photogrammetry and Remote Sensing and Spatial Information Sciences, v. 33, p. 148-155, 2000

BATISTELLA, M.; ROBESON, S.; MORAN, E. F. Settlement design, forest fragmentation, and landscape change in Rondônia, Amazônia. Photogrammetric Engineering and Remote Sensing, v. 69, n. 7, p. 805-812, 2003.

BATTESE, G. E. Frontier production functions and technical efficiency: A survey of empirical applications in agricultural economics. Agricultural Economics, v. 7, p. 185-208, 1992.

BAYARSAIHAN, T.; COELLI, T. J. Productivity growth in pre-1990 Mongolian agriculture: spiralling disaster or emerging success? Agricultural Economics, v. 28, n. 2, p. 121-137, 2003.

BRAVO-URETA, B. E.; PINHEIRO, A. E. Efficiency analysis of developing country agriculture: a review of the frontier function literature. Agricultural and Resource Economics Review, v. 22, p. 88-101, 1993.

BUREAU, J. C.; FÄRE, R.; GROSSKOPF, S. A comparison of three nonparametric measures of productivity growth in European and United-States agriculture. Journal of Agricultural Economics, v. 46, n. 3, p. 309-326, 1995.

CHARNES, A.; COOPER, W. W.; RHODES, E. Measuring the efficiency of decision-making units. European Journal of Operational Research, v. 2, p. 429-444, 1978.

CHAVAS, J.; ALIBER, M. An analysis of economic efficiency in agriculture: A nonparametric approach. Journal of Agriculture and Resource Economics, v. 18, p. 1-16, 1993.

COELLI, T. J. Recent developments in frontier modelling and efficiency measurement. Australian Journal of Agricultural Economics, v. 39, n. 3, p. 219-245, 1995.

COELLI, T. J. Measurement of total factor productivity growth and biases in technological change in Western Australian agriculture. Journal of Applied Econometrics, v. 11, n. 1, p. 77-91, 1996.

COELLI, T. J.;PRASADARAO, D.S.; O'DONNELL, C. J.; BATTESE, G. E. An Introduction to Efficiency and Productivity Analysis. 2. ed. New York: Springer, 2005. $349 \mathrm{p}$.

COELLI, T. J.; RAO, D. S. P. Total factor productivity growth in agriculture: A Malmquist index analysis of 93 countries, 1980-2000. Agricultural Economics, v. 32, p. 115-134, 2005.

COOK, W. D.; ZHU, J. Classifying inputs and outputs in data envelopment analysis. European Journal of Operational Research, v. 180, n. 2, p. 692-699, 2007.

COOPER, W. W.; RUIZ, J. L.; SIRVENT, I. Choosing weights from alternative optimal solutions of dual multiplier models in DEA. European Journal of Operational Research, v. 180, n. 1, p. 443-458, 2007

COOPER, W. W.; SEIFORD, L. M.; TONE, K. Data Envelopment Analysis: a comprehensive text with models, applications, references and DEASolver software. 2nd edition. Boston: Kluwer Academic Publishers, 2006. 490p.

DRUCK, S.; CARVALHO, M. S.; CÂMARA, G.; MONTEIRO, A. V. M. Análise Espacial de Dados Geográficos. Brasília: Embrapa, 2004. 209 p.

DYSON, R. G.; ALLEN, R.; CAMANHO, A. S.; PODINOVSKI, V. V.; SARRICO, C. S.; SHALE, E. A. Pitfalls and protocols in DEA. European Journal of Operational Research, v. 132, n. 2, p. 245-259, 2001.

ESRI. ARCMAP TM8.3. C1999-2002. Redlands. CDROM. Windows. 2002.

EVENSON, R. E.; AVILA, A. F. D. Total factor productivity growth in agriculture: The role of technological capital. Fontagro Seminar. Competitividad rural: Retos, Oportunidades y Recursos para la Innovación Tecnológica Agrícola en América Latina y el Caribe. Lima: Fondo Regional de Tecnología Agropecuaria. 2004. 39 p.

FÄRE, R.; GRABOWSKI, R.; GROSSKOPF, S. Technical efficiency in Philippine agriculture. Applied Economics, v. 17, p. 205-214, 1985.

FÄRE, R.; GROSSKOPF, S.; NORRIS, M.; ZHANG, Z. Productivity growth, technical progress, and efficiency change in industrialized countries. The American Economic Review, v. 84, n. 1, p. 66-83, 1994.
FÄRE, R.; GROSSKOPF, S.; WEBER, W. The effect of risk-based capital requirements on profit efficiency in banking. Applied Economics, v. 36 , n. 15, p. 1731-1743, 2004.

GASQUES, J. G.; BASTOS, E. T.; BACCHI, M. P. R.; CONCEIÇÃO, J. C. P. R. Condicionantes da produtividade da agricultura brasileira. Revista de Política Agrícola, ano 13, n. 3, p. 763-90, 2004.

GASQUES, J. G.; CONCEIÇÃO, J. C. P. R. Crescimento e produtividade da agricultura brasileira. Brasília: Instituto de Pesquisa Econômica Aplicada, 1997. 21 p. (Texto para Discussão, 502).

GOMES, E. G. Uso de modelos DEA em agricultura: Revisão da literatura. Engevista, v. 10, p. 27-51, 2008.

GOMES, E. G.; MANGABEIRA, J. A. C. Uso de análise de envoltória de dados em agricultura: o caso de Holambra. Engevista, v. 6, n. 1, p. 19-27, 2004

GOMES, E. G.; MANGABEIRA, J. A. C.; SOARES DE MELLO; J. C. C. B. Análise de envoltória de dados para avaliação de eficiência e caracterização de tipologias em agricultura: um estudo de caso. Revista de Economia e Sociologia Rural, v. 43 , n. 4 , p. $607-631,2005 a$

GOMES, E.G.; MANGABEIRA, J.A.C.; VALLADARES, G. S.; BATISTELLA, M. Eficiência técnica e fertilidade do solo: estudo da relação espacial para o caso da agricultura de Machadinho d'Oeste, RO. In: CONGRESSO DA SOCIEDADE BRASILEIRA DE ECONOMIA E SOCIOLOGIA RURAL, 43., 2005, Ribeirão Preto. Anais..., 2005b.

GOMES, E. G.; SOARES DE MELLO, J. C. C. B.; MANGABEIRA, J. A. C. Índice multicritério de bem estar social rural em um município da região amazônica. Pesquisa Operacional, v. 28 , n. 1, p. 141-160, 2008.

GOMES, E. G.; SOARES DE MELLO, J. C. C. B.; SOUZA, G. S.; ANGULO MEZA, L.; MANGABEIRA, J. A. C. Efficiency and sustainability assessment for a group of farmers in the Brazilian Amazon. Annals of Operations Research, v. 169, p. 167-181, 2009. [DOI:10.1007/ s10479-008-0390-6].

GOMES, E. G.; VALLADARES, G. S.; MANGABEIRA, J. A. C.; GREGO, C. R.; BATISTELLA, M.; MIRANDA, E. E. Relação espacial de atributos edáficos e eficiência produtiva 
para o caso de lotes agrícolas em Machadinho d'Oeste, RO. In: SIMPÓSIO BRASILEIRO DE SENSORIAMENTO REMOTO, 13., 2007, Florianópolis. Anais..., p. 221-223, 2007.

HELFAND, S. M.; LEVINE, E. S. Farm size and the determinants of productive efficiency in the Brazilian Center-West. Agricultural Economics, v. 31, n. 2-3, p. 241-249, 2004.

HOFFMANN, R.; JAMAS, A. L. A produtividade da terra e do trabalho na agricultura de 332 microrregiões do Brasil. In: CONGRESSO BRASILEIRO DE ECONOMIA E SOCIOLOGIA RURAL, 28., Florianópolis, 1990. Anais..., 1990.

HOLLINGSWORTH, G.; SMITH, P. Use of ratios in data envelopment analysis. Applied Economics Letters, v. 10, p. 733-735, 2003.

LINS, M. P. E.; MOREIRA, M. C. B. IO-Stepwise: Um procedimento para seleção de variáveis em Análise Envoltória de Dados. Pesquisa Operacional, v. 19, n. 1, 1999.

LISSITSA, A.; ODENING, M. Efficiency and total factor productivity in Ukrainian agriculture in transition. Agricultural Economics, v. 32, n. 3, p. 311-325, 2005.

MANGABEIRA, J. A. C.; MIRANDA, E. E.; GOMES, E. G. Perfil agrossocioeconômico dos produtores rurais de Machadinho d'Oeste (RO), em 2002. Campinas: Embrapa Monitoramento por Satélite, 2005. 114 p., il. (Documentos, 38).

MIRANDA, E. E. (org.) Sustentabilidade Agrícola na Amazônia: 20 anos de monitoramento da agricultura em Machadinho d'Oeste-RO. Campinas: Embrapa Monitoramento por Satélite, 2005. 1 CD-Rom.

MIRANDA, E. E.; MANGABEIRA, J. A. C.; BATISTELLA, M.; DORADO, A. J. Diagnóstico agroecológico e socioeconômico dos produtos rurais de Machadinho d'Oeste (RO), em 1999. Campinas: Embrapa Monitoramento por Satélite, 2002. 88 p. (Documentos, 18).

MIRANDA, E. E.; MANGABEIRA, J. A. C; MATTOS, C.; DORADO, A. J. Perfil agroecologico e socioeconômico de pequenos produtores rurais: o caso de Machadinho d'Oeste, Rondônia. Campinas: Ecoforça/Embrapa-NMA, 1997. 117p. il.
PEREIRA, M. F.; SILVEIRA, J. S. T.; LANZER, E. A.; SAMOHYL, R. W. Productivity growth and technological progress in the Brazilian agricultural sector. Pesquisa Operacional, v. 22, n. 2, p. 133-146, 2002.

PEROBELLI, F. S.; ALMEIDA, E. S.; ALVIM, M. I. S. A. Análise espacial da produtividade do setor agrícola brasileiro: 1991-2003. In: CONGRESSO BRASILEIRO DE ECONOMIA E SOCIOLOGIA RURAL, 43., 2005, Ribeirão Preto. Anais..., 2005.

PODINOVSKI, V. V.; THANASSOULIS, E. Improving discrimination in data envelopment analysis: Some practical suggestions. Journal of Productivity Analysis, v. 28, n. 1-2, p. 117126, 2007.

RAY, S. Measurement and test of efficiency of farmers in linear programming models: a study of West Bengal farms. Oxford Bulletin of Economics and Statistics, n. 47, p. 371-386, 1985.

RIOS, L. R.; MAÇADA, A. C. G. Analysing the relative efficiency of container terminals of Mercosur using DEA. Maritime Economics and Logistics, v. 8, n. 4, p. 331-346, 2006.

ROSEN, D.; SCHAFFNIT, C.; PARADI, J. C. Marginal rates and two-dimensional level curves in DEA. Journal of Productivity Analysis, v. 9, n. 3, p. 205-232, 1998.

SENRA, L. F. A. C.; NANCI, L. C.; SOARES DE MELLO, J. C. C. B.; ANGULO MEZA, L. . Estudo sobre métodos de seleção de variáveis em DEA. Pesquisa Operacional, v. 27, p. 191-207, 2007.

SILVEIRA, J. Q.; PEREIRA, E. R.; CORREIA, T. C. V. D.; SOARES DE MELLO, J. C. C. B.; CLÍMACO, J. C. N.; ANGULO MEZA, L. Avaliação da eficiência das companhias aéreas brasileiras com uma variação do modelo de Li e Reeves. Engevista (UFF), v. 10, n. 2, p. 145-155, 2008.

SOARES DE MELLO, J. C. C. B.; ANGULOMEZA, L.; GOMES, E. G.; SERAPIÃO, B. P.; LINS, M. P. E. Análise de Envoltória de Dados no estudo da eficiência e dos benchmarks para companhias aéreas brasileiras. Pesquisa Operacional, v. 23, n. 2, p. 325-345, 2003.

SOARES DE MELLO, J. C. C. B.; GOMES, E. G.; BIONDI NETO, L.; LINS, M. P. E. Suavização da fronteira DEA: 0 caso BCC tridimensional. Investigação Operacional, v. 24, p. 89-107, 2004.
SOARES DE MELLO, J. C. C. B.; LINS, M. P. E.; GOMES, E. G. Construction of a smoothed DEA frontier. Pesquisa Operacional, v. 22, n. 2, p. 183-201, 2002.

SUDIT, F. E. Productivity measurement in industrial operations. European Journal of Operational Research, v. 85, p. 435-453, 1995.

THIRTLE, C.; PIESSE, J.; SCHIMMELPFENNIG, $D$. Modeling the length and shape of the R\&D lag: An application to UK agricultural productivity. Agricultural Economics, v. 39, n. 1, p. 73-85, 2008.

TIPI, T.; REHBER, E. Measuring technical efficiency and total factor productivity in agriculture: The case of the South Marmara region of Turkey. New Zealand Journal of Agricultural Research, v. 49, n. 2, p. 137145, 2006.

TORESAN, L. Sustentabilidade e desempenho produtivo na agricultura: uma abordagem multidimensional aplicada a empresas agrícolas. Tese (Doutorado em Engenharia de Produção) - Universidade Federal de Santa Catarina, Florianópolis, 1998.

TULKENS, H.; VANDEN EECKAUT, P. Nonparametric efficiency, progress and regress measures for panel data: Methodological aspects. European Journal of Operational Research, v. 80, n. 3, p. 474-499, 1995.

TUPY, O.; YAMAGUCHI, L. C. T. Identificando benchmarks na produção de leite. Revista de Economia e Sociologia Rural, v. 40, n. 1, p. 81-96, 2002.

VALLADARES, G. S.; BOGNOLA, I. A.; GOVÊA, J. R. F. Levantamento de reconhecimento de solos de média intensidade da Gleba Machadinho, Ro. Documentos, n. 30. Campinas: Embrapa Monitoramento por Satélite, 2003. 92 p., il. Disponível em: http://www.cnpm.embrapa.br/ publica/download/d30_machasolos_vf.pdf. Acesso em: 14 dez. 2006.

VALLADARES, G. S.; GOMES, E. G.; MANGABEIRA, J. A. C.; GREGO, C. R.; BATISTELLA, M.; MIRANDA, E. E.; HOTT, M. C. Geoestatística na avaliação da fertilidade do solo e eficiência técnica para a cultura do arroz em Machadinho D oeste, RO. In: FERTBIO-2006, 2006, Bonito. Anais..., 2006. 
VICENTE, J. R. Comparações de produtividade agrícola entre as unidades da federação, 1970-95. In: CONGRESSO BRASILEIRO DE ECONOMIA ESOCIOLOGIA RURAL, 43., 2005, Ribeirão Preto. Anais..., 2005.

VIEIRA, S. R. Geoestatística em estudos de variabilidade espacial do solo. In: NOVAIS, R. F.; ALVAREZ, V. H.; SCHAEFER, G. R.
(Eds.) Tópicos em Ciência do Solo. Viçosa: Sociedade Brasileira de Ciência do solo, v. 1, p. 1-54, 2000.

VIEIRA, S. R.; MILLETE, J.; TOPP, G. C.; REYNOLDS, W. D. Handbook for geostatistical analysis of variability in soil and climate data. In: Alvarez, V. V .H.; Schaefer, C. E. G. R.; Barros, N. F.; Mello, J. W. V.; Costa, L. M.
(Eds.) Tópicos em Ciência do Solo. Viçosa: Sociedade Brasileira de Ciência do Solo, v. 2, p. 1-45, 2002.

WAGNER, J. M.; SHIMSHAK, D. G. Stepwise selection of variables in data envelopment analysis: Procedures and managerial perspectives. European Journal of Operational Research, v. 180, n. 1, p. 57-67, 2007.

\section{AGRADECIMENTOS}

Ao CNPq, pelo apoio financeiro. À Embrapa Monitoramento por Satélite, pelo uso dos dados.

\section{SOBRE OS AUTORES}

\section{Eliane Gonçalves Gomes}

Empresa Brasileira de Pesquisa Agropecuária (Embrapa) - SGE

End.: Parque Estação Biológica (PqEB), Av. W3 Norte final - Asa Norte - Brasília - DF - 70770-901

Tel.: (61) 3448-4476

Fax: (61) 3347-4480

E-mail: eliane.gomes@embrapa.br

\section{Célia Regina Grego}

Embrapa Monitoramento por Satélite

End.: Av. Soldado Passarinho, 303 - Fazenda Chapadão - Campinas - SP - 13070-115 - Brasil

E-mail: crgrego@cnpm.embrapa.br

\section{João Carlos Correia Baptista Soares de Mello}

Universidade Federal Fluminense - Departamento de Engenharia de Produção

End.: Rua Passo da Pátria, 156 - São Domingos - Niterói - RJ - 24210-240

E-mail: jcsmello@pesquisador.cnpq.br

\section{Gustavo Souza Valladares}

Universidade Federal do Ceará - Centro de Ciências Agrárias - Departamento de Ciências do Solo End.: Av. Mister Hull, 2977, Campus do Pici, Bloco 807 - CP 12.168 - Fortaleza - CE - 60021-970 E-mail: valladares@ufc.br

\section{João Alfredo de Carvalho Mangabeira}

Embrapa Monitoramento por Satélite

End.: Av. Soldado Passarinho, 303 - Fazenda Chapadão - Campinas - SP - 13070-115 - Brasil

E-mail: manga@cnpm.embrapa.br

\section{Evaristo Eduardo de Miranda}

Embrapa Monitoramento por Satélite

End.: Av. Soldado Passarinho, 303 - Fazenda Chapadão - Campinas - SP - 13070-115 - Brasil

E-mail: mir@cnpm.embrapa.br 